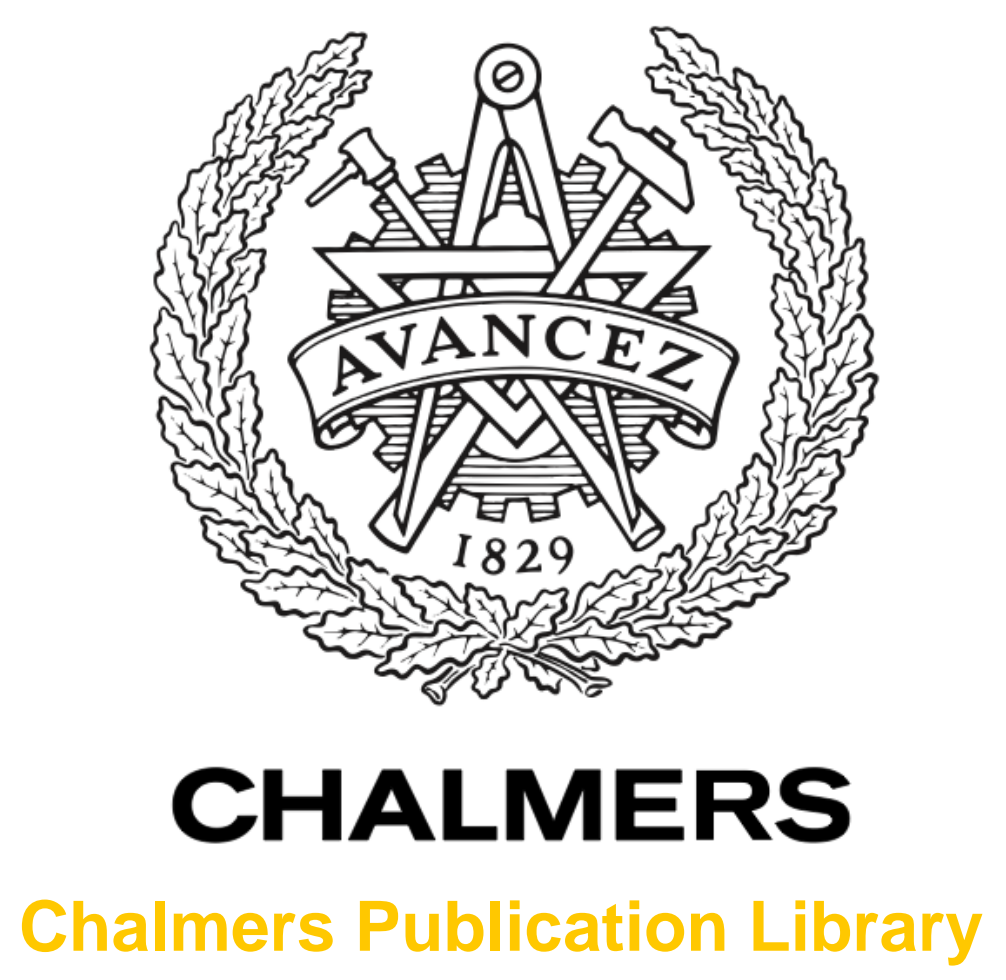

\title{
Prediction of punching behaviour of RC slabs using continuum non-linear FE analysis
}

This document has been downloaded from Chalmers Publication Library (CPL). It is the author's version of a work that was accepted for publication in:

Engineering Structures (ISSN: 0141-0296)

Citation for the published paper:

Shu, J. ; Plos, M. ; Zandi Hanjari, K. et al. (2016) "Prediction of punching behaviour of RC slabs using continuum non-linear FE analysis". Engineering Structures, vol. 125 pp. 15-25.

http://dx.doi.org/10.1016/j.engstruct.2016.06.044

Downloaded from: http://publications.lib.chalmers.se/publication/243701

Notice: Changes introduced as a result of publishing processes such as copy-editing and formatting may not be reflected in this document. For a definitive version of this work, please refer to the published source. Please note that access to the published version might require a subscription.

Chalmers Publication Library (CPL) offers the possibility of retrieving research publications produced at Chalmers University of Technology. It covers all types of publications: articles, dissertations, licentiate theses, masters theses, conference papers, reports etc. Since 2006 it is the official tool for Chalmers official publication statistics. To ensure that Chalmers research results are disseminated as widely as possible, an Open Access Policy has been adopted.

The CPL service is administrated and maintained by Chalmers Library. 


\title{
Prediction of punching behaviour of RC slabs using continuum non- linear FE analysis
}

\author{
Jiangpeng Shu ${ }^{\mathrm{a}, *}$, Mario Plos $^{\mathrm{a}}$, Kamyab Zandi ${ }^{\mathrm{a}, \mathrm{b}}$, Morgan Johansson ${ }^{\mathrm{a}, \mathrm{c}}$, Filip Nilenius ${ }^{\mathrm{a}}$ \\ ${ }^{a}$ Department of Civil and Environmental Engineering, Chalmers University of Technology, 41296 Gothenburg, Sweden \\ ${ }^{b}$ Concrete and Stone Group, CBI Swedish Cement and Concrete Research Institute, 50115 Borås, Sweden \\ c ÅF, Infrastructure AB, Grafiska Vägen 2, 40551 Göteborg, Sweden
}

\section{A R T I C L E I N F O}

\section{Article history:}

Received 11 April 2016

Revised 9 June 2016

Accepted 27 June 2016

Available online 12 July 2016

\section{Keywords:}

RC slabs

Punching failure

Finite element analysis

Structural behaviour

\begin{abstract}
A B S T R A C T
Failure of reinforced concrete $(\mathrm{RC})$ slabs without shear reinforcement in punching has been a challenging problem for nonlinear finite element (FE) analysis. To improve the analysis approach, this study was conducted by developing a nonlinear FE analysis method for slabs subjected to punching failure without shear reinforcement, using three-dimensional continuum elements. The influence of several modelling choices were investigated by comparing such results as loadcarrying capacity, load-deflection response and crack pattern from the FE analyses with available experimental data. The proposed method shows the possibility of accurately predicting the load-carrying capacity and realistically describing the behaviour of slabs.
\end{abstract}

(c) 2016 Published by Elsevier Ltd.

\section{Introduction}

Existing infrastructure represents a substantial part of societal assets and existing bridges represent a huge capital that needs to be well administrated. Bridge deck slabs are among the most exposed bridge parts and are often critical to damage [1]. Consequently, it is important to examine if current assessment and analysis methods are appropriate. In order to develop a systematic approach for the assessment of reinforced concrete (RC) slabs, Plos et al. have developed a "Multi-level Assessment Strategy"; see Fig. 1 [2]. The strategy provides the engineering community with a framework for using successively improved structural analysis methods for an enhanced assessment in a straight forward manner. In Plos et al. [2] five analysis levels, I-V, on increasing levels if detailing are presented. Case studies have shown that more advanced methods normally yield an improved understanding of the structural response and are capable of demonstrating higher, yet conservative, predictions of the load-carrying capacity [2,3]. A methodology to model RC slabs subjected to bending and shear type failures using continuum element in nonlinear finite element (FE) analysis (Level IV \& V) has been devised by the authors [4,5]. However, at Level IV and V the study of RC slabs subjected to punching failure is a more challenging task and needs to be investigated and included in the assessment strategy.

\footnotetext{
* Corresponding author.

E-mail address: jiangpeng.shu@chalmers.se (J. Shu).
}

Previously, several numerical investigations have been carried out to apply nonlinear FE analysis to predict punching behaviour of RC slabs. Among these, studies using two-dimensional (2D) models have been conducted, e.g. Menétry [6] and Hallgren [7]. A separate application was investigated by those who implement layered shell element which takes into account an out-of-plane shear response and allows the implementation of threedimensional (3D) constitutive models, e.g. Polak [8]. Compared to 2D element models, a 3D element model offers a higher flexibility and accuracy in the modelling of out-of-plane behaviour of reinforced concrete structures and generally results in more realistic results [2,9-12]. However, even though nonlinear FE analysis has increasingly been used to analyse RC slabs, yet a guide on how to perform these analyses is not available to engineers.

The overall aim of this study was to investigate the feasibility of predicting the response of RC slabs without shear reinforcement subjected to punching using continuum elements in nonlinear FE analysis (Level IV and V according to Fig. 1 [2]), and providing recommendations for the choice of modelling alternatives. In the future, these recommendations along with the "Multi-level Assessment Strategy" [2] and other researches [13,14] should complement more general guidelines already available in the literature, such as fib: bulletin 12 [15], fib: bulletin 45 [16] and Hendriks et al. [17]. This study was conducted by carrying out nonlinear FE analysis for RC slabs without shear reinforcement which has been tested by Guandalini and Muttoni $[18,19]$. The predicted load-deflection relation and crack pattern from FE analysis have 


$\begin{array}{ll}\beta & \text { shear retention factors } \\ \mathrm{V} & \begin{array}{l}\text { punching capacity } \\ \mathrm{V}_{\mathrm{R} . \mathrm{EXP}}\end{array} \\ \mathrm{V}_{\mathrm{R} . \mathrm{FEA}} & \begin{array}{l}\text { punching capacity of slab obtained from experiment } \\ \text { punching capacity of slab obtained from finite element } \\ \text { analysis }\end{array} \\ \mathrm{V}_{\mathrm{R} . \mathrm{EC} 2} & \begin{array}{l}\text { punching capacity of slab obtained from calculation } \\ \text { according to Eurocode } 2\end{array} \\ b_{0} & \begin{array}{l}\text { control perimeter for calculation of punching according } \\ \text { to Eurocode } 2\end{array} \\ \xi & \begin{array}{l}\text { factor accounting for size effect according to Eurocode } 2\end{array}\end{array}$

been compared with corresponding experimental data. The influence on the structural behaviour of different material models and modelling choices was studied. Several parameters including size effect and reinforcement ratio, which influence the punching behaviour itself, as well as the possibility to predict the response by FE analysis, were investigated in the study.

\section{Methodology}

This study was conducted by carrying out numerical analyses on previously tested RC slabs without shear reinforcement. The experiment series carried out by Guandalini and Muttoni [18,19] was used for comparison and verification of the modelling method used in the numerical study. It was selected because it presented RC slabs subjected to punching failure with varying properties such as dimension of slabs, concrete strength and reinforcement ratio. Prior to the numerical study, a literature study of the experiments of Guandalini and Muttoni [18,19] was made.
The process of the numerical study is illustrated in Fig. 2. In the first step a reference model, developed according to the modelling method previously proposed by Shu et al. [5], was used to simulate the tested slabs PG1 and PG2b [18]. These two slabs were selected because they represent two distinct cases: slab PG1 that failed due to brittle punching (punching occurred before yielding of flexural reinforcement), and slab PG2b that failed due to ductile punching (punching occurred after the yielding of flexural reinforcement). The results of the FE analyses, including load-deflection relation and crack patterns, were compared with experimental data. In case the results did not agree sufficiently well with the experiments, the modelling choices would have to be investigated to improve the reference model until a sufficiently good agreement was reached. As a second step, the calibrated reference model was applied to all the slabs from PG1 to PG11 and all the analysed results were compared to corresponding experiment results and predictions made based on Eurocode 2 [20]. In the third step, a parameter study was made. The results from FE analysis were analysed based

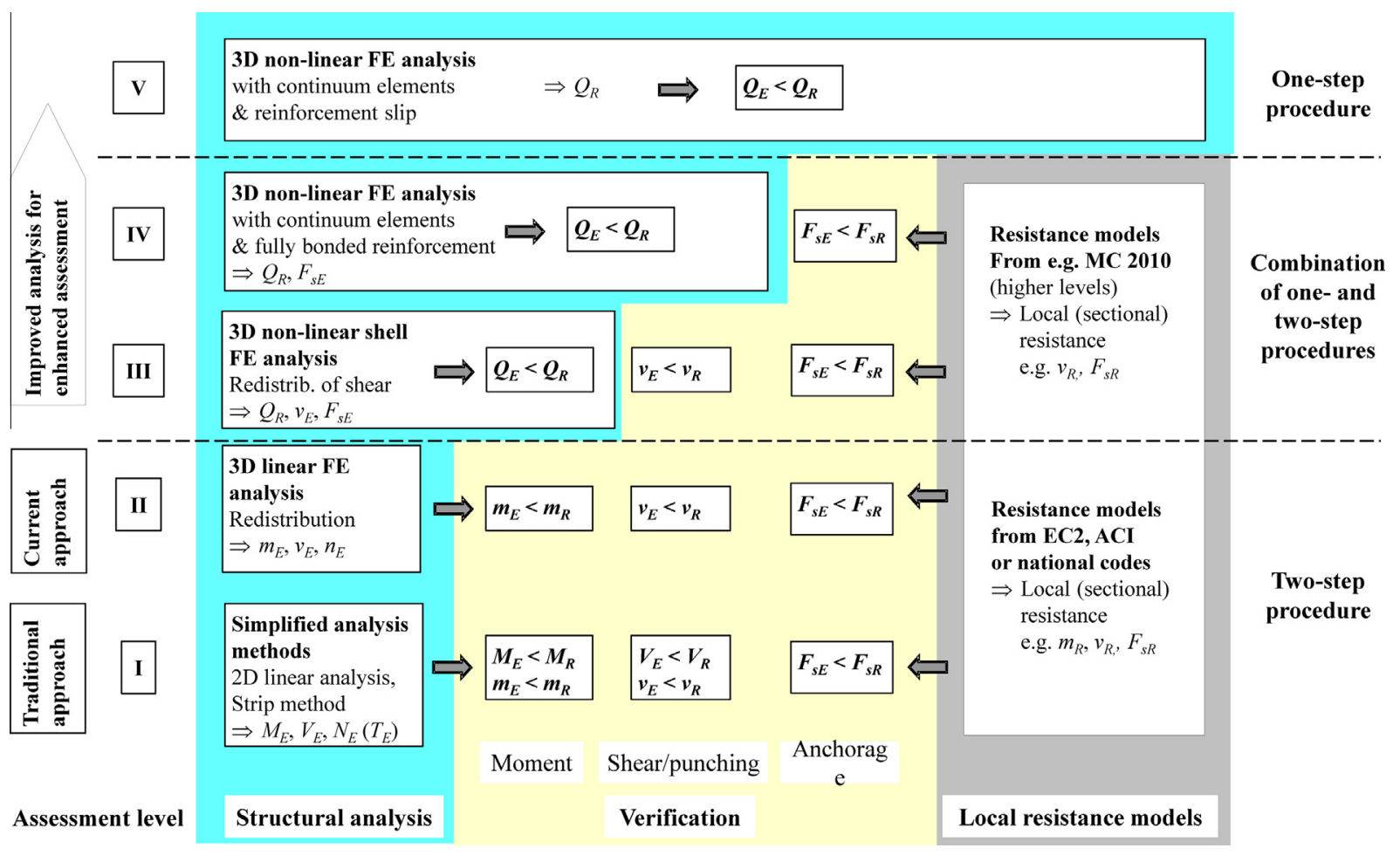

Fig. 1. Scheme for multi-level assessment of reinforced concrete bridge deck slabs. From Plos et al. [2]. 


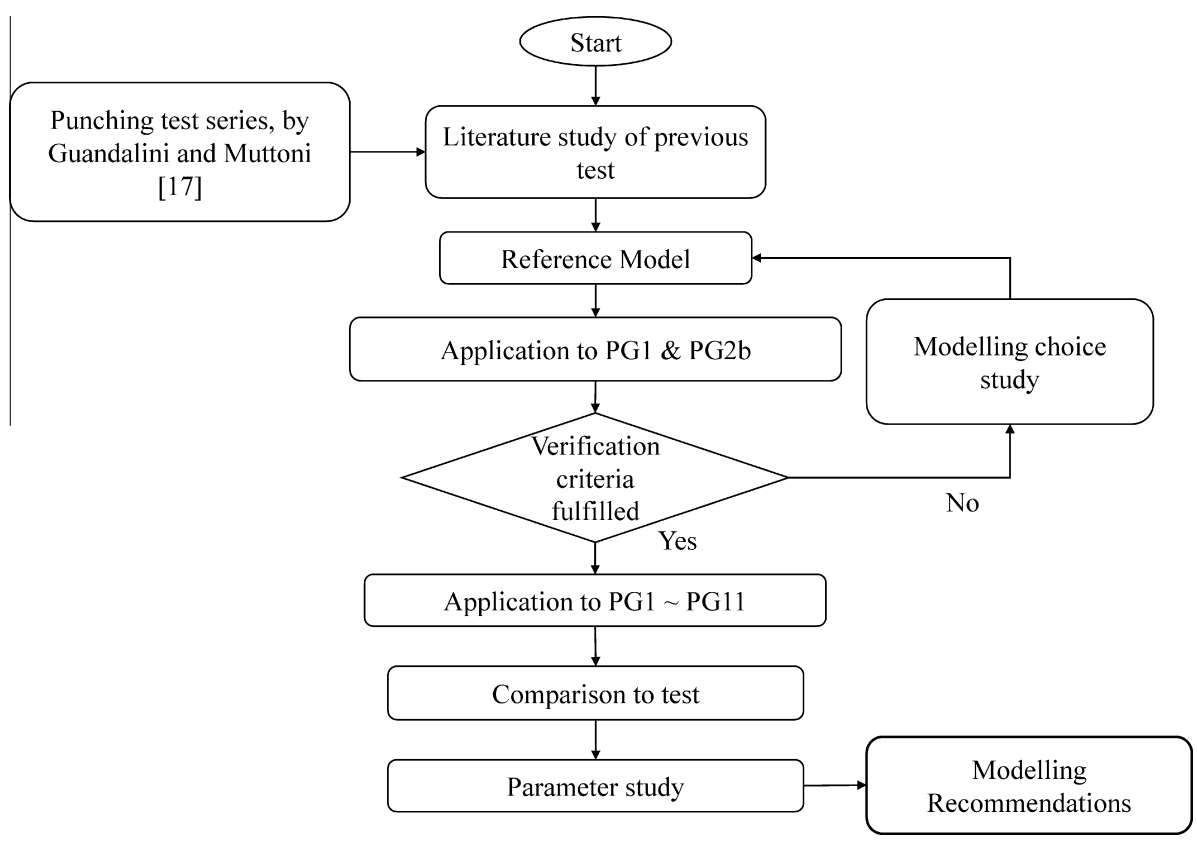

Fig. 2. Process of the numerical study performed.

on parameters that have been reported to have influence on punching response, for example, size effect and reinforcement ratio. In the parameter study $\mathrm{FE}$ analysis results were compared with experiments as well as predictions according to Eurocode 2 [20] to verify that the FE model reflects the structural behaviour realistically. In the fourth and final step, modelling recommendations were formulated based on the reference model and results of the analyses.

\section{Description of experiments}

In 2004, Guandalini and Muttoni [19] carried out a series of bench mark tests on slabs at École Polytechnique Fédérale de Lausanne (EPFL); see Fig. 3. The aim of these tests was to investigate the behaviour of RC slabs with different dimensions, compressive strength of concrete and reinforcement ratios, failing in punching shear. The test series consisted of eleven reinforced concrete slabs representing internal slab-column connections without transverse reinforcement in the slabs. The square columns were cast together with the slabs with side lengths $c$ slightly larger than the thicknesses $h$ of the slabs. Three sizes of the tested specimens were used: "full-size" specimens (PG1, PG2b, PG4, PG5, PG10 and PG11), "double-size" specimen (PG3) and "half-size" specimens (PG6, PG7, PG8 and PG9). Table 1 shows the main dimensions, reinforcement amounts and material parameters of each specimen. The specimens were loaded through eight concentrated forces acting on the perimeter of the specimen; the load was introduced using four hydraulic jacks placed underneath the laboratory floor.
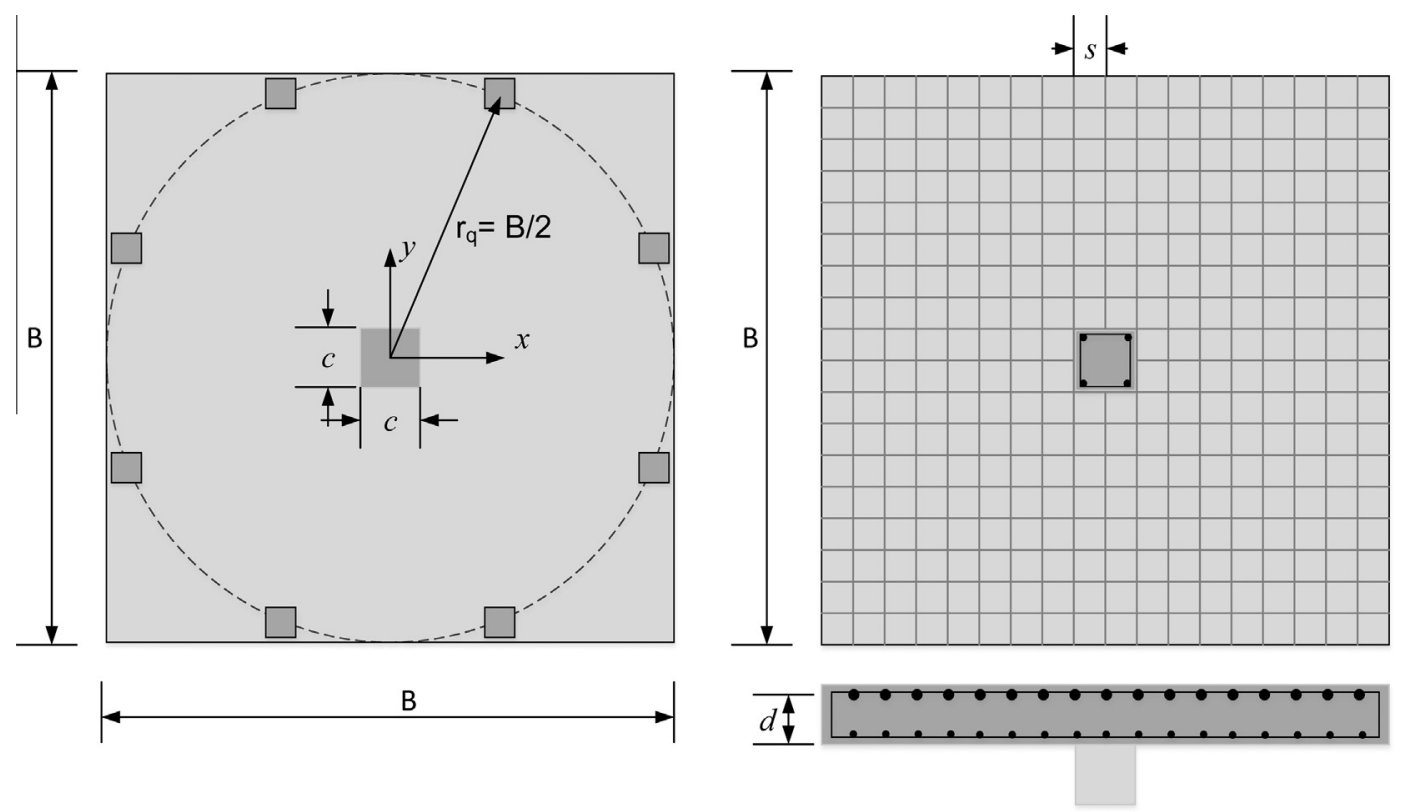

Fig. 3. The dimensions and rebar layout of the experimental slabs, adopted from Guandalini and Muttoni [18]; B is length of sides and $d$ is effective depth of the slab. 
Table 1

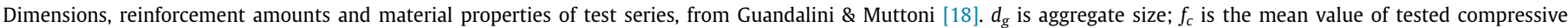
strength of concrete; $\rho$ is reinforcement ratio; $f_{y}$ and $f_{u}$ is yield and ultimate strength of reinforcement steel.

\begin{tabular}{|c|c|c|c|c|c|c|c|c|}
\hline \multicolumn{2}{|c|}{ Specimen dimension (m) B $\times \mathrm{B} \times h$} & \multicolumn{3}{|c|}{ Concrete } & \multicolumn{4}{|l|}{ Reinforcing steel } \\
\hline & & $d(\mathrm{~m})$ & $f_{c}(\mathrm{MPa})$ & $d_{g}(\mathrm{~mm})$ & Reinforcement & $\rho(\%)$ & $f_{y}(\mathrm{MPa})$ & $f_{u}(\mathrm{MPa})$ \\
\hline \multirow{6}{*}{$\begin{array}{l}\text { Full size specimens } \\
\begin{array}{l}3 \times 3 \times 0.25 \\
c=0.26\end{array}\end{array}$} & PG1 & \multirow[t]{6}{*}{0.21} & 27.6 & \multirow[t]{2}{*}{16} & Ø20 s100 & $1.5 \%$ & 573 & 656 \\
\hline & PG2b & & 40.5 & & $\varnothing 10$ s150 & $0.25 \%$ & 552 & 612 \\
\hline & PG4 & & 32.2 & \multirow[t]{2}{*}{4} & $\varnothing 10$ s150 & $0.25 \%$ & 541 & 603 \\
\hline & PG5 & & 29.3 & & $\varnothing 10$ s115 & $0.33 \%$ & 555 & 659 \\
\hline & PG10 & & 28.5 & \multirow[t]{3}{*}{16} & Ø10 s115 & $0.33 \%$ & 577 & 648 \\
\hline & PG11 & & 31.5 & & Ø16/18 s145 & $0.75 \%$ & 570 & 684 \\
\hline $\begin{array}{l}\text { Double size } \\
\qquad \begin{array}{l}6 \times 6 \times 0.5 \\
c=0.52\end{array}\end{array}$ & PG3 & 0.456 & 32.4 & & Ø16 s135 & $0.33 \%$ & 520 & 607 \\
\hline \multirow{4}{*}{$\begin{array}{l}\text { Half size } \\
\qquad \begin{array}{l}1.5 \times 1.5 \times 0.125 \\
c=0.125\end{array}\end{array}$} & PG6 & 0.096 & \multirow[t]{4}{*}{34.7} & & $\varnothing 14$ s110 & $1.5 \%$ & 526 & 607 \\
\hline & PG7 & 0.1 & & & $\varnothing 10$ s105 & $0.75 \%$ & 550 & 623 \\
\hline & PG8 & 0.117 & & & Ø8 s155 & $0.28 \%$ & 525 & 586 \\
\hline & PG9 & 0.117 & & & $\varnothing 8$ s196 & $0.22 \%$ & 525 & 586 \\
\hline
\end{tabular}

During the punching test, the load was increased at a constant rate all the way up to failure. For all specimens, the final failure mode was punching shear, with a clearly delimited punching cone. More information about the experiments and their results can be found in Guandalini and Muttoni [18,19].

\section{Numerical study}

\subsection{Finite element model}

The finite element software DIANA 9.5 [21] was utilized to model the slabs, using 3D tetrahedron 4-node element models, as displayed in Fig. 4. Due to symmetry and the need to reduce the computation time, only a quarter of the slab was included in the FE model. On the symmetry faces, all displacements perpendicular to the cross-sections were fixed. The reinforcement was modelled as fully bonded embedded reinforcement bars, which means the stiffness of reinforcement was added to the concrete element directly. The loading steel plates above the slab were included and vertical displacement was fixed at the top of the loading plates. Interface elements including Mohr-Coulomb friction model were used between the concrete and steel plates. The effect of the interface element has been investigated in Shu et al. [5]. To model the loading, all the nodes on the bottom surface of the column were tied to the centre node so that they had the same vertical displacement; during the analysis the centre node was given a controlled displacement upwards. An incremental, iterative static analysis was performed using specified increment sizes. Each increment was equivalent to a vertical displacement of $0.1 \mathrm{~mm}$ until the first crack initiated. After that, to save computation time, the increments were increased to $0.5 \mathrm{~mm}$ to save computation time. The analyses were carried out using a regular Newton-Raphson iteration method based on force or energy convergence criteria with a tolerance of 0.01 . The FE model described above were applied to all the tested slabs.

\subsection{Reference model}

As indicated in chapter 2 , a reference model was selected based on the studies of Shu et al. [22] and Plos et al. [2] to perform the analyses at the first step. The reference model which is presented here was already calibrated by a parameter study according to Fig. 2. In the reference model, the 1 st order tetrahedron element with seven layers of elements along the thickness was used. Regarding the material model of concrete, the Total Strain rotating crack model [23] with a crack band width approach was used. In this approach, the crack width $w$ was related to the crack strain $\varepsilon_{c r}$ perpendicular to the crack via a characteristic length - the crack bandwidth $h_{b}$. The reinforcement was modelled assuming complete interaction with the surrounding concrete; consequently, the distribution of one crack would be smeared over the mean crack distance, i.e. $h_{b}=$ mean crack distance. That means the crack will localized in several elements instead of one, which has been verified in Shu et al. [5]. Values of mean crack distance $h_{b}$ were calculated according to Eurocode 2 [20] for each slabs and are presented in Table 2. Fig. 5(a) shows the tensile response of concrete according to Hordijk et al. [24], used for the reference model. In

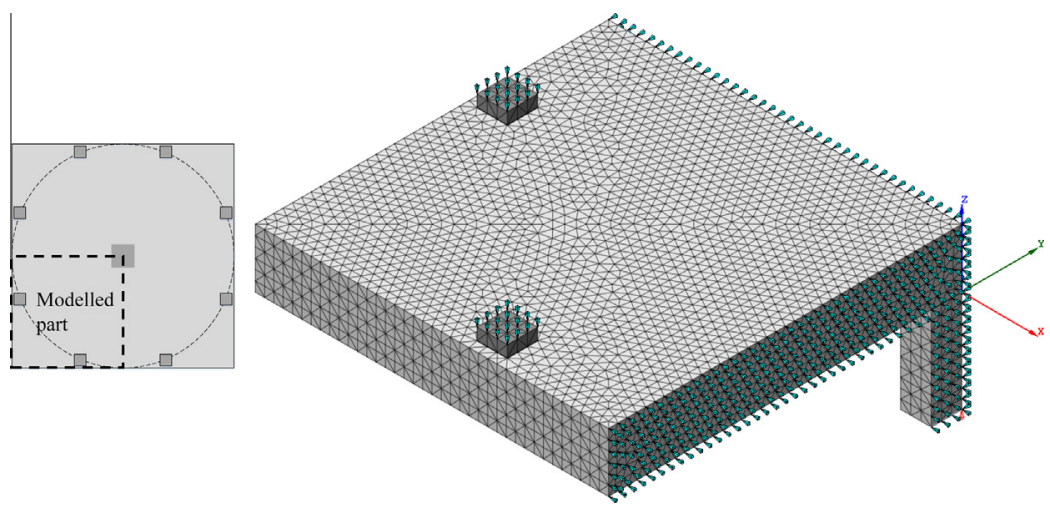

Fig. 4. FE model of a quarter of slab PG1. Boundary conditions are indicated by arrows in the directions with fixed degrees of freedom. 
Table 2

Values of mean crack distance $h_{b}$ and Mode I fracture energy $G_{f}$.

\begin{tabular}{|c|c|c|c|c|c|c|c|c|c|c|c|}
\hline & PG1 & PG2b & PG3 & PG4 & PG5 & PG6 & PG7 & PG8 & PG9 & PG10 & PG11 \\
\hline$h_{b}(\mathrm{~mm})$ & 78 & 113 & 78 & 113 & 100 & 96 & 104 & 90 & 99 & 100 & 90 \\
\hline$G_{f}(\mathrm{~N} / \mathrm{m})$ & 61 & 80 & 68 & 57 & 53 & 72 & 72 & 72 & 72 & 62 & 67 \\
\hline
\end{tabular}
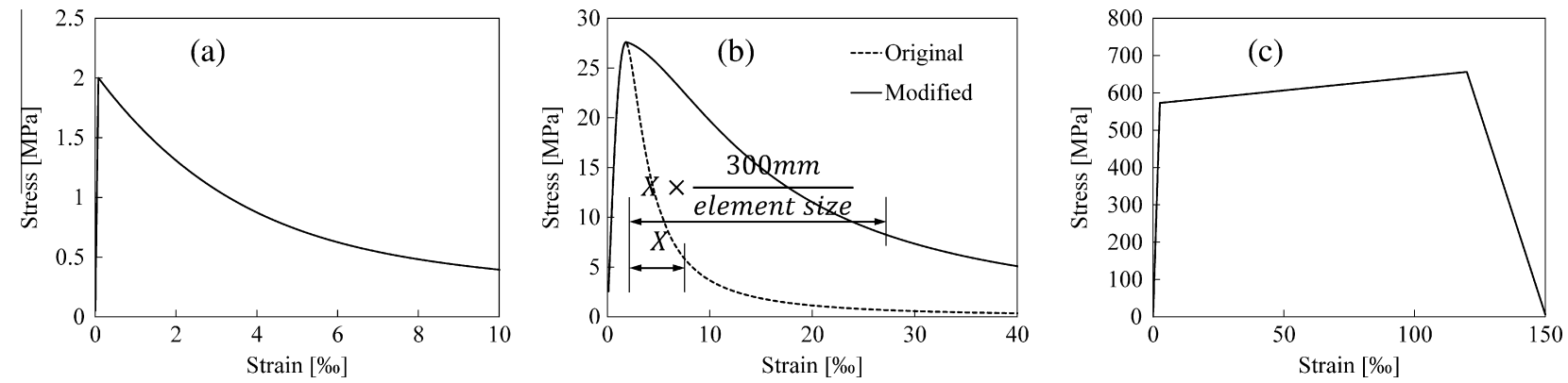

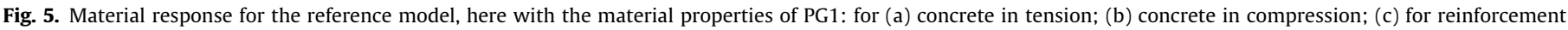
steel.

the reference model, the Mode I fracture energy was calculated according to Model Code 1990 [25]; see Table 2.

The behaviour of concrete in compression was described according to Thorenfeldt [26]. When the stress-strain relationship was used in numerical analyses, the localization of deformations in compressive failure had to be taken into account. The compression softening behaviour was related to the boundary conditions and size of the specimen in the material tests [27]. Consequently, as the stress-strain relation has been calibrated by measurements in compression tests on $300 \mathrm{~mm}$ long cylinders [26], the softening branch had to be modified for the concrete element size used in the FE model [28]; see Fig. 5(b), in which $X$ indicates original strain (based on test measurements). This was done by assuming that the compressive failure would take place in one element row. This assumption was later found to be correct in the analysis. The influence of lateral confinement in compression was taken into account according to the model developed by Selby and Vecchio [29].

The material property of the reinforcement was described by a von Mises plasticity model, including strain hardening, using values obtained from material tests; see Fig. 5(c).

\subsection{Alternative modelling choices}

As described in Fig. 2, an effort was made to evaluate the modelling choices with the aim to improve the reference model. In order to evaluate the influence of various modelling choices, parameters which may possibly influence the shear behaviour were varied one at the time; see Fig. 6. First of all, a mesh sensitivity analysis were carried out to verify the FE model. Element types including 1 st order tetrahedron element, 1 st order brick element and 2nd order brick element were tested and results compared. Then, the size of the 1st order tetrahedron elements were varied by adopting different $h / L$ ratios ( $h=$ thickness of slab, $L=$ cube root of volume of solid element). When brick element was used, $h / L=5$ for 1 st element and $h / L=5$ for 2 nd order element was used since the model size otherwise increased too much.

With the Total Strain rotating crack model, the modelling choices investigated was an alternatively determined fracture energy, a different tensile response of concrete, and an alternative lateral confinement model for compressive strength of concrete. The Mode I fracture energy according to Model Code 2010 [30]

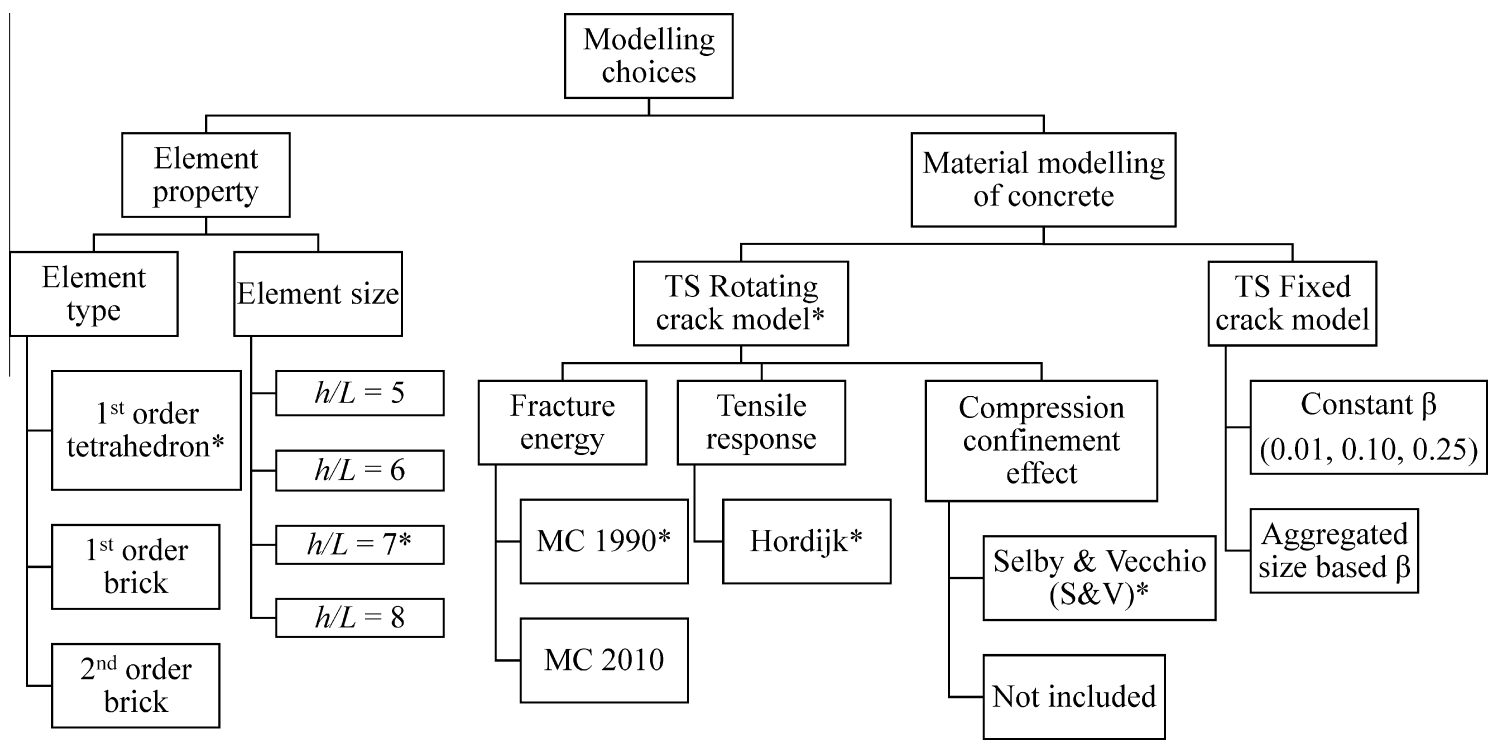

Fig. 6. Varied modelling choices: the alternatives with ${ }^{*}$ were used for the reference model while the others were used for comparative models. 
was also checked since the calculated fracture energy values increased significantly compared with Model Code 1990 [25]. To take into account the effect of lateral confinement for compressive response, the model developed by Selby and Vecchio [31] was included in the reference model because the concrete element near the column was subjected to high confinement in the experiment. It was excluded in the comparative model to see the effect.

For comparison, a Total Strain fixed crack model [21] with various shear retention factors was also used when the modelling choices were evaluated. According to Eder et al. [12], the best choice for retention factor depends on many parameters, including concrete properties, the type of structure and its failure mode, as well as software implementation. In the current study, constant values of $\beta=0.01,0.1$ and 0.25 were adopted since it was recommended to use $0 \leqslant \beta \leqslant 0.25$ by Rots [32]. Another way to calculate the shear retention factor $\beta$ based on aggregate size (see Eq. (1), $d_{\text {agg }}=$ aggregate size, $\varepsilon_{n}=$ total strain, $h=$ crack bandwidth) was also used in the study.

$\beta=1-\left(\frac{2}{d_{a g g}}\right) \varepsilon_{n} h$

\section{Results and discussion}

As indicated in Fig. 2, the initial reference model was calibrated by a modelling choice study. In this chapter, results obtained from the calibrated reference model is presented first, followed by results from modelling choice variations. Thereafter, results from analyses of all experiments in the test series studied are presented and finally the results of the parameter study.

\subsection{Load-deflection response and crack pattern from reference model}

Comparisons between load-deflection response of the calibrated reference model and the experiments are shown in Fig. 7. For PG1, the stiffness of the two curves are in good agreement but the final loadcarrying capacity predicted by the reference FE model is underestimated by $28 \%$. For PG 2 b, both stiffness and load-carrying capacity of the two curves match quite well even though the final deflection is underestimated by the reference FE model.

The crack patterns after failure from the reference model and the experiments were also compared; see Fig. 8. Fig. 8(a1) represents the crack pattern at the cross section of slab PG1 from the FE analysis and the experiment, respectively. This indicates that the reference FE model is able to simulate the propagation of inclined critical shear cracks in general even though the direction of the critical cracks are not the same; in the experiment, the inclined shear crack is somewhat flatter than that in the FE analy- sis. Fig. 8(a2) represents the crack pattern at the top surface of slab PG1 from the FE analysis and the experiment, respectively. It shows that the reference FE model is capable of predicting the major crack pattern but not each individual crack in detail. Fig. 8 (b1) and Fig. 8(b2) show the comparison for PG2b. It is observed that the angle of the shear crack is predicted more accurately than for PG1 and more extensive bending cracking was obtained from the FE analysis.

The study above shows that the calibrated reference model is capable of describing the structural behaviour in general, including the load-deflection response and crack pattern. However, the results indicate that reference model underestimate the load carrying capacity for slabs with brittle punching failures, like PG1. This could be due to the scatter in experiment results. However, before the reference model was determined, an effort was made to improve the reference model by varying some modelling choices.

\subsection{Element properties}

In order to carry out a mesh sensitivity analysis, element properties such as element type and element order were investigated for both PG1 and PG2b. Element types including 1st order tetrahedron element, 1 st order brick element and 2nd order brick element were tested and the load-deflection curves are shown in Fig. 9 (a) and (b). They indicate that both the 1st order tetrahedron element and 1st order brick element yield similar results, but the 2nd order brick element renders a somewhat softer behaviour and lower load-carrying capacity. Considering the FE analysis using continuum elements carried out by Shu et al.[5,33], all three element types are potentially used in engineering practice; the difference however should be noticed by engineers: the 1 st order elements usually render stiffer results than 2nd order elements while tetrahedral shaped element usually render more freedom for crack propagation. One reason the 1 st order tetrahedron element was selected here was that it has more freedom to be used in rather complicated geometry and skewed shape. In addition, the size of the elements was varied to adopt different $h / L$ ratios. Load displacement curves in Fig. 9(c) and (d) indicate that the FE mesh with $h / L=7$ was fine enough to provide accurate results.

\subsection{Material input for FE models}

The alternative modelling choices for the Total Strain rotating crack model included fracture energy, tensile response of concrete as well as a lateral confinement model for the compressive strength of concrete. The results of analyses with these three modelling choices were compared with the reference analysis as well as with experimental results; see Fig. 10(a) for PG1 and Fig. 10(b) for PG2b. The Mode I fracture energy of concrete for PG1 and PG2b
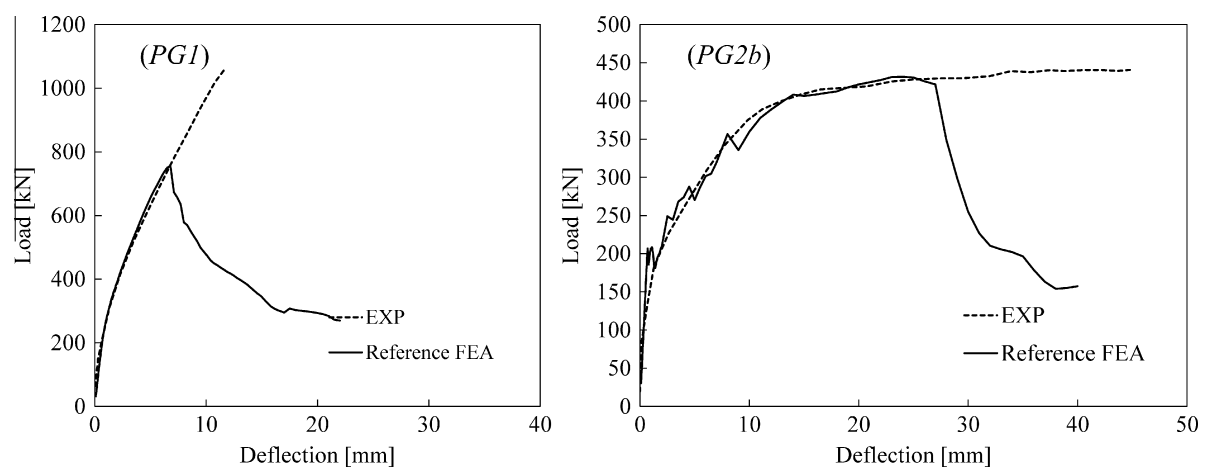

Fig. 7. Comparison between load-deflection curve of reference model and experiment for PG1 and PG2b. 


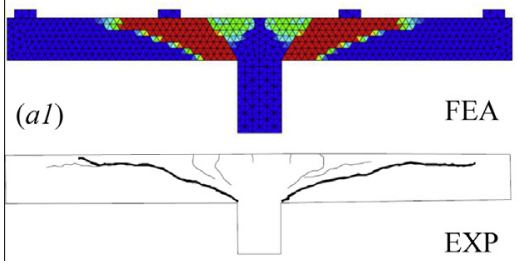

$$
\text { PG1 }
$$
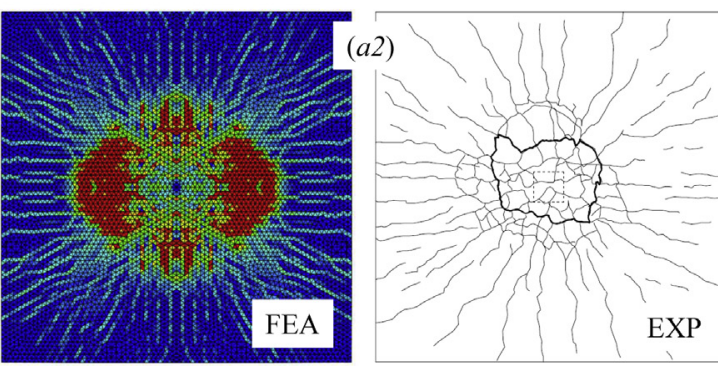

$\mathrm{PG} 2 \mathrm{~b}$
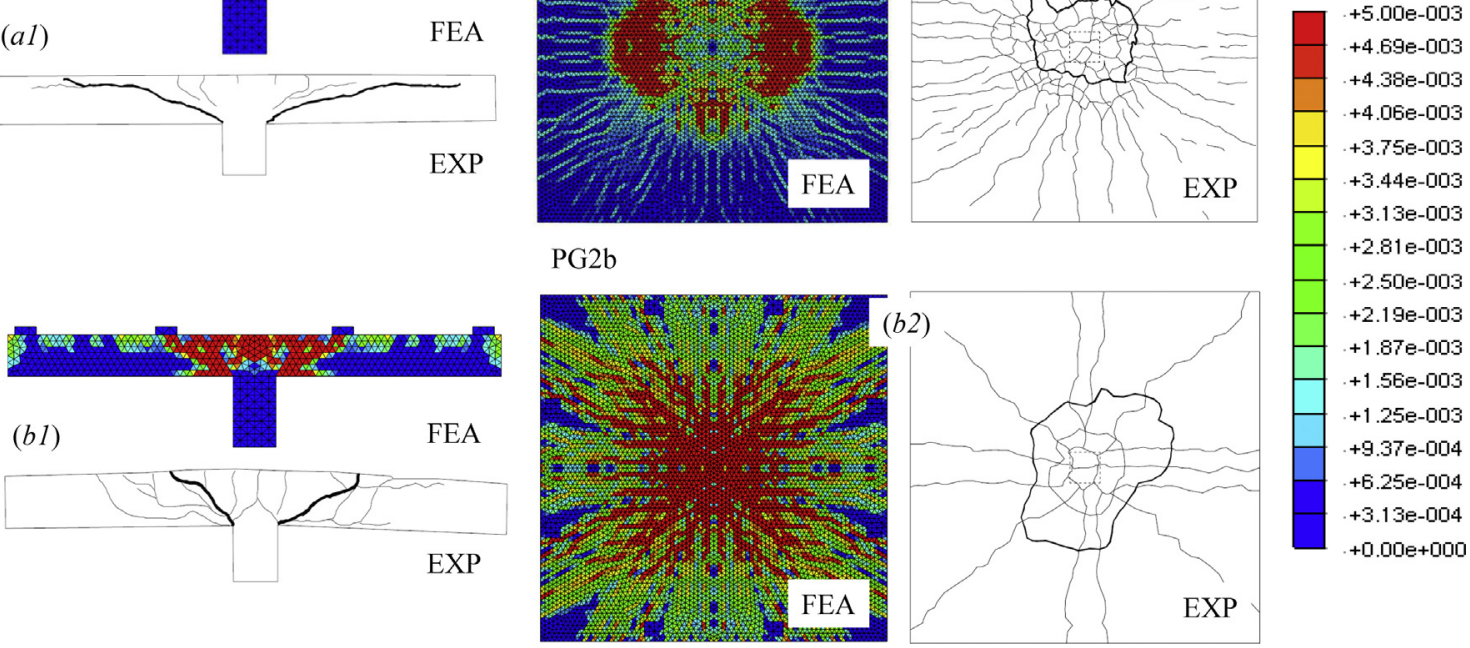

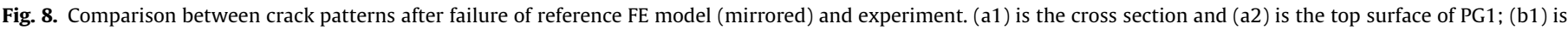
the cross section and (b2) is the top surface for PG2b.
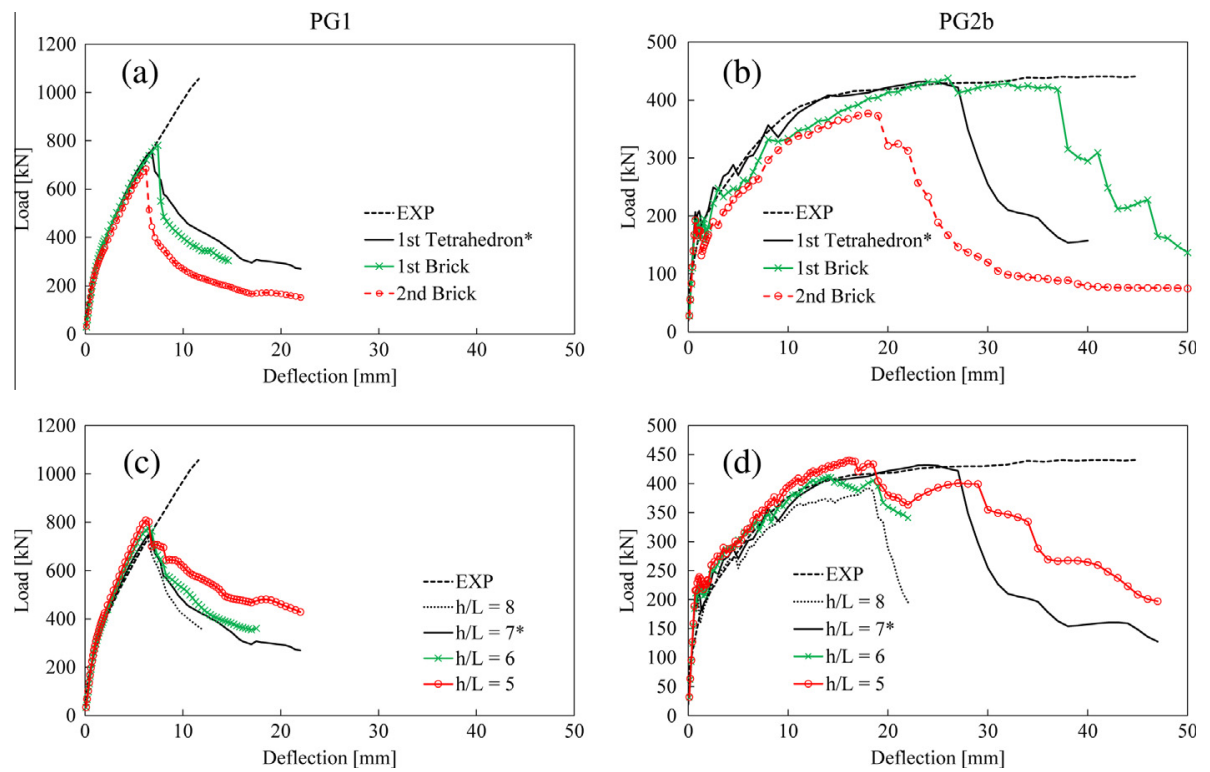

Fig. 9. (a) Element type analysis for PG1; (b) Element type analysis for PG2b; (c) Element size analysis for PG1; (d) Element size analysis for PG2b.
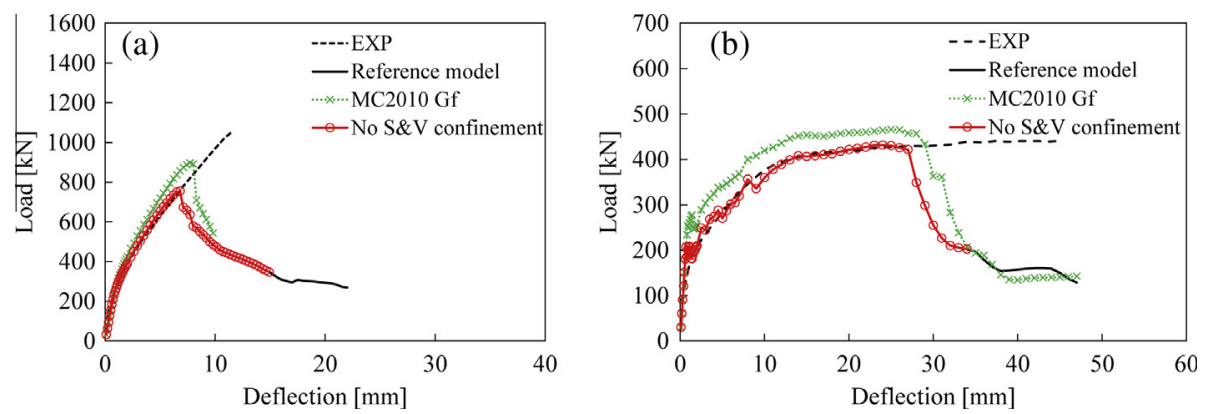

Fig. 10. The results of analyses using Total Strain rotating crack model with different modelling choices; (a) for PG1 and (b) for PG2b. 

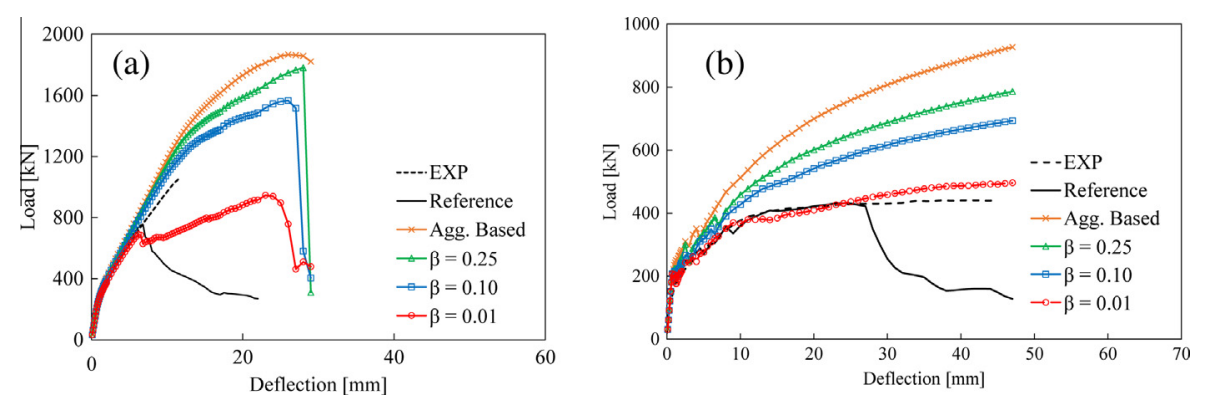

Fig. 11. The results of analyses using the Total Strain fixed crack model with different modelling choices; (a) for PG1 and (b) for PG2b.

were calculated as $133 \mathrm{~N} / \mathrm{m}$ and $142 \mathrm{~N} / \mathrm{m}$, respectively, according to Model Code 2010 [30] instead of $61 \mathrm{~N} / \mathrm{m}$ and $80 \mathrm{~N} / \mathrm{m}$ according to Model Code 1990 [25], leading to an increase of around 10\% in the load-carrying capacity. Since the slabs tested contained concrete with different aggregate sizes, Model Code 1990 [25] which takes this into account was found to be more appropriate for the current work. The effect of confinement on the load-deflection curve seems to be negligible.

The modelling choices for the Total Strain fixed crack model included different constant shear retention factors $\beta$ and aggregate size based shear retention factors (see Eq. (1)) $\beta=0-1$. The results of the analyses using these modelling choices were compared with the experimental results and the reference model and are shown in Fig. 11. It was observed that only the model with constant $\beta=0.01$ yields reasonable results whereas higher $\beta$ values, including the aggregate size based $\beta$, yield overestimation of the load-carrying capacity. Based on these analyses, it could be concluded that the punching behaviour of RC slabs using the fixed crack model was too sensitive to the shear retention factor $\beta$. Instead, the rotating crack model seems more reliable if the shear retention factor $\beta$ cannot not be evaluated accurately for the specific case.

\subsection{Results of analyses for all experiments of the test series}

According to the evaluation of the modelling choices described above, the reference model has been verified to be able to reflect the structural behaviour of RC slabs subjected to punching in general. Considering the scatter in the experiment, the result from the reference analyses was judged to be satisfactory enough. Consequently, the modelling method used in reference model was adopted to analyse the experiments of all the punching test series by Guandalini and Muttoni [19]; according to step 2 in chapter 2. All load-deflection curves were compared to experiments and presented in Fig. 12. It was observed that the reference model reflected the structural behaviour at a high level of accuracy.

Table 3 presents the load-carrying capacity according to the FE analyses and comparison to the experimental results and calculated results according to Eurocode 2 [20]. The results show that the proposed reference model is capable of predicting punching capacity rather accurately and somewhat conservatively, with a small coefficient of variation (0.12). Compared with Eurocode 2 [20], the load-carrying capacity was closer to the experiment, less conservative and the coefficient of variation was smaller.

\subsection{Parameters study}

The flexural reinforcement ratio affects the punching strength of RC slabs. Such an effect has been reported in the literature $[34,35]$ and has been included in Eurocode 2 [20] but not in ACI 318-08 [36]. Fig. 13 presents the relation between the flexural reinforcement ratio and the accuracy of the punching capacity as predicted by FE analysis and Eurocode 2, for PG1 to PG11. It was observed that the scatter in the prediction increased as the flexural reinforcement ratio increased.

In order to investigate how well the influence of the flexural reinforcement ratio on the punching response could be reflected in the FE analysis, the relation between nominal punching strength and deflection was studied for four experiments with different reinforcement ratios; see Fig. 14. The nominal punching strength was used to exclude the influence of specimen size and compressive strength of concrete from the load-deflection response. Fig. 14 shows that the FE analysis qualitatively reflects the same change in structural behaviour as the experiments, even though the capacity is underestimated for high reinforcement ratios; when the reinforcement ratio increases from $0.25 \%$ (PG2b) to 1.5\% (PG1), both the stiffness and punching strength increase while the ductility decreases.

In Fig. 15, the nominal punching capacity for the same experiments are compared for experiments, FE analyses and calculations according to Eurocode 2. In the FE analyses, the flexural reinforcement also affected the punching crack even though the dowel effect was not included in the model, for example, the shear crack width decreased when flexural reinforcement ratio increased. The results show that the FE analyses are in good agreement with both the experiments and with Eurocode 2 with respect to the influence of reinforcement ratio.

Bažant and Cao [37] stated that the nominal strength decreases with an increase in the structural size. This phenomena is termed as size effect in the literature. The size effect is an established phenomena for punching in slabs $[11,20,38,35]$. It was investigated how well the FE analysis results reflect the size effect compared to the experiments and Eurocode 2. In the experiment of Guandalini and Muttoni [19], the influence of size effect on punching shear has been studied by including tests with three specimen sizes with varying slab thicknesses: $0.125 \mathrm{~m}, 0.25 \mathrm{~m}$ and $0.5 \mathrm{~m}$ (here represented by PG6, PG1 and PG3, respectively). By comparing the nominal punching strength excluding the influence of the reinforcement ratio and compressive strength of concrete, see Fig. 16, it was shown that the influence of the size effect was similar in the FE analyses and the experiments; however, in Eurocode 2 , the size effect is smaller.

\section{Conclusions}

To summarize, the overall aim of this study was to investigate the feasibility to predict the structural behaviour of RC slabs without shear reinforcement subjected to punching failure using continuum elements in nonlinear FE analysis, and to provide recommendations concerning to the choice of modelling alternatives. The research was carried out by a systematic numerical study including varying modelling choices, a parameter study and comparison with experimental as results as well as with analytical calculations according to Eurocode 2. 

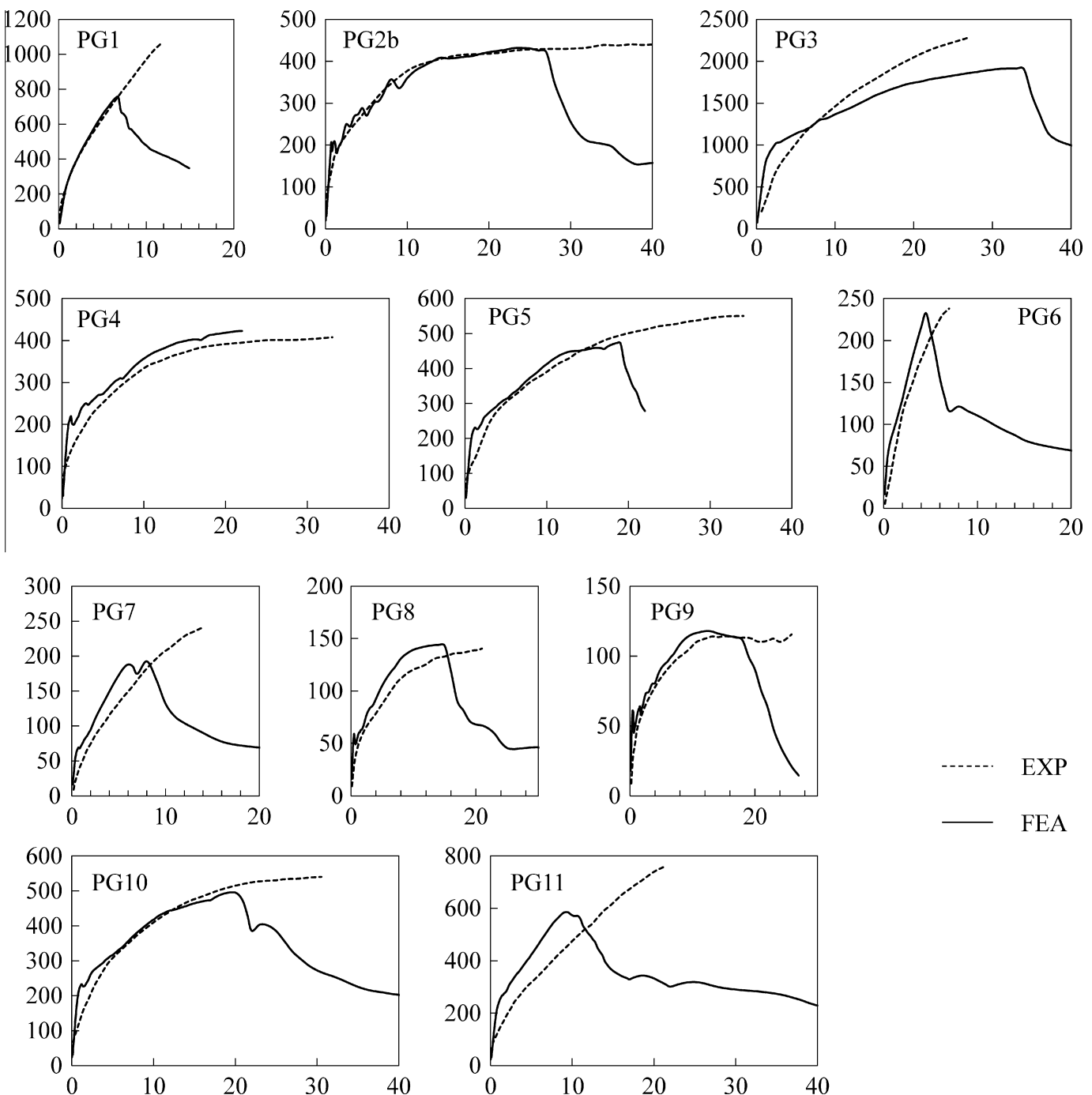

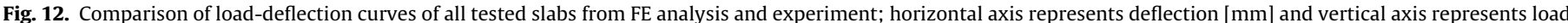
$[\mathrm{kN}]$.

Table 3

Comparison between FE analysis (FEA) results, EC2 results and experiment results.

\begin{tabular}{lccccc}
\hline Specimens & $\mathrm{V}_{\text {R.EXP }}(\mathrm{kN})$ & $\mathrm{V}_{\text {R.FEA }}(\mathrm{kN})$ & $\mathrm{V}_{\text {R.EC2 }}(\mathrm{kN})$ & $\frac{V_{\text {R.EPP }}}{V_{\text {R.FEA }}}$ & $\frac{V_{\text {REXP }}}{V_{\text {R.EC }}}$ \\
\hline PG1 & 1023 & 755 & 950 & 1.35 & 1.61 \\
PG2b & 440 & 431 & 594 & 1.02 & 1.11 \\
PG3 & 2153 & 1910 & 2347 & 1.13 & 1.38 \\
PG4 & 408 & 423 & 550 & 0.96 & 1.11 \\
PG5 & 550 & 498 & 585 & 1.10 & 1.41 \\
PG6 & 238 & 232 & 223 & 1.03 & 1.60 \\
PG7 & 241 & 192 & 189 & 1.26 & 1.91 \\
PG8 & 140 & 144 & 179 & 0.97 & 1.17 \\
PG9 & 115 & 118 & 165 & 0.97 & 1.05 \\
PG10 & 540 & 496 & 580 & 1.09 & 1.40 \\
PG11 & 763 & 586 & 787 & 1.30 & 1.45 \\
Average & & & & 1.10 & 1.38 \\
Coefficient of variation & & & 0.12 & 0.18
\end{tabular}

By comparing the results of the FE analyses with experiments, it was concluded that the reference model was capable of predicting the punching capacity and crack pattern rather accurately. When compared with the calculations according to Eurocode 2, continuum FE analysis are able to capture punching failure with lower deviation and smaller scatter.

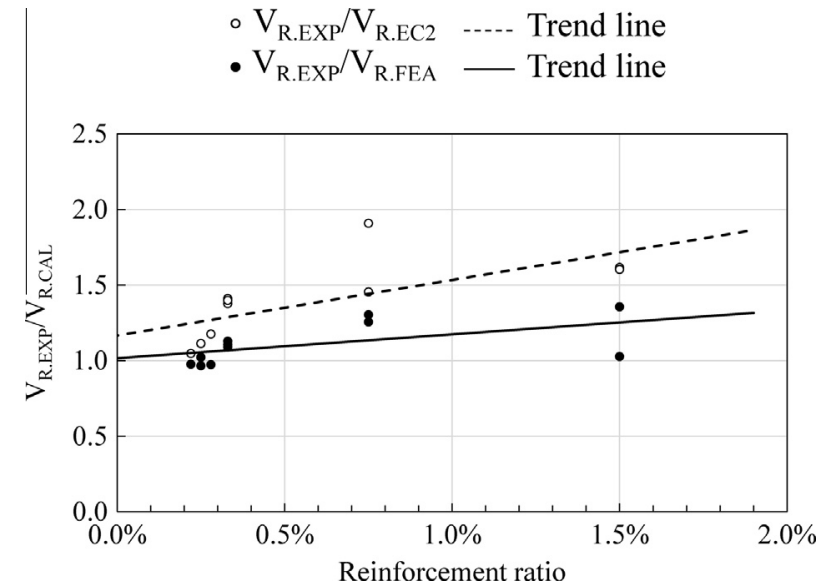

Fig. 13. The relation between and $\mathrm{V}_{\mathrm{EXP}} / \mathrm{V}_{\mathrm{FEA}}$ and reinforcement ratio.

The results from the study of modelling choices show that the structural behaviour predicted by the FE analysis was significantly affected by different modelling choices. For the Total Strain rotating crack model, the fracture energy was an important influencing 

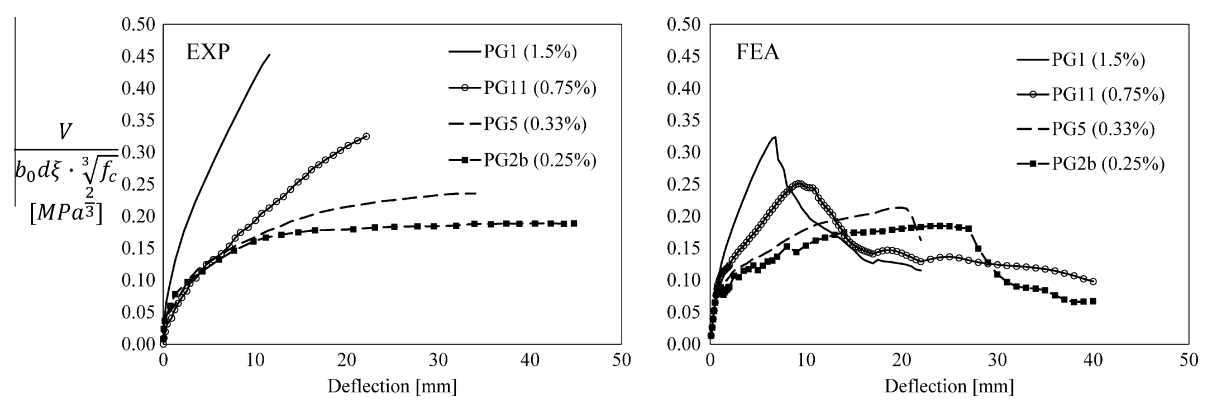

Fig. 14. Comparison of nominal load-deflection curve of four slabs with varying reinforcement ratios, obtained from experiment and FE analysis.

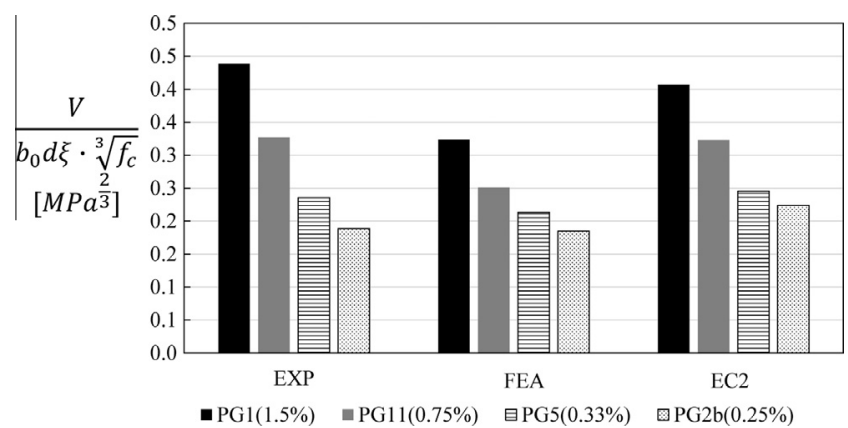

Fig. 15. Comparison of nominal punching capacity of four slabs with varying reinforcement ratios, obtained from experiment, FE analysis and Eurocode 2.

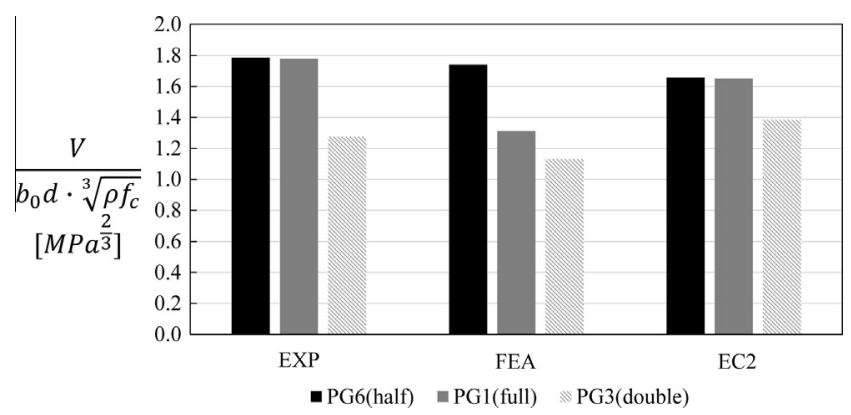

Fig. 16. Comparison of nominal punching strength of three slabs with varying slab thickness, obtained from experiment, FE analysis and Eurocode 2.

factor. For the Total Strain fixed crack model, the punching capacity was considerably affected by the shear retention. Thus, the rotating crack model is easier to be used if the shear retention factor $\beta$ cannot not be determined accurately for the specific case.

The parameter study shows that the reference FE model does not only provide a good estimation of load-carrying capacity, but also reflect the influence of parameters such as the size effect and the flexural reinforcement ratio. Results of the FE analyses are in good agreement with experiments and calculations based on Eurocode 2 [20].

Consequently, as a reliable modelling method for RC slabs subjected to punching failure, the modelling choices adopted in the reference model can be recommended: (a) a total strain rotating crack model can be used for concrete and fully bonded reinforcement model can be used for reinforcement steel; (b) first order four-node tetrahedral elements with at least seven element layers over the cross-section height are sufficient; (c) the crack band width should be estimated as the mean crack distance if fully bonded reinforcement is used; (d) fracture energy calculated by Model Code 1990 is preferred to be used since it accounts for the aggregate size; (e) lateral confinement model for compressive strength of concrete is also recommended to be used since it reflects real behaviour.

\section{Acknowledgement}

The authors would like to gratefully acknowledge the support and funding from Swedish Transport Administration (Trafikverket), which made the research possible.

\section{References}

[1] SB-ICA. Guideline for inspection and condition assessment. Sustainable bridges: report; 2007.

[2] Plos M, Shu J, Zandi K, Lundgren K. A multi-level structural assessment strategy for reinforced concrete bridge deck slabs. Struct Infrastruct Eng 2016;2479:1-19.

[3] SB-4.5. Non-linear analysis and remaining fatigue life of reinforced concrete bridges. Sustainable bridges: report; 2007.

[4] Shu J. Structural analysis of existing RC bridge deck slabs. Chalmers University of Technology, Licentiate Thesis, Gothenburg; 2015.

[5] Shu J, Fall D, Plos M, Zandi K, Lundgren K. Development of modelling strategies for two-way RC slabs. Eng Struct 2015:101:439-49.

[6] Menétrey P, Walther R, Zimmermann T, Willam KJ, Regan PE. Simulation of punching failure in reinforced-concrete structures. J Struct Eng 1997;123 (5):652-9.

[7] Hallgren M. Punching shear capacity of reinforced high-strength concrete slabs Doctoral thesis. Stockholm (Sweden): Kungliga Tekniska Hogskolan; 1996.

[8] Polak MA. Shell finite element analysis of RC plates supported on columns for punching shear and flexure. Eng Comput 2005;22(4):409-28.

[9] Ozbolt J, Vocke H, Eligehausen R. Three-dimensional numerical analysis of punching failure. Trita-BKN Bull 2000;57:65-74.

[10] Zheng Y, Robinson D, Taylor S, Cleland D. Finite element investigation of the structural behaviour of deck slabs in composite bridges. Eng Struct Aug. 2009;31(8):1762-76.

[11] Amir S. Compressive membrane action in prestressed concrete deck slabs PhD thesis. Delft: Delft University of Technology; 2014.

[12] Eder MA, Vollum RL, Elghazouli aY, Abdel-Fattah T. Modelling and experimental assessment of punching shear in flat slabs with shearheads. Eng Struct 2010;32(12):3911-24.

[13] Engen M, Hendriks MAN, Øverli JA, Åldstedt E. Solution strategy for non-linear finite element analyses of large reinforced concrete structures. Struct Concr 2015;16(3):389-97.

[14] Belletti B, Damoni C, Hendriks M, de Boer A. Analytical and numerical evaluation of the design shear resistance of reinforced concrete slabs. Struct Conrete 2014:317-30.

[15] CEB-FIP. fib bulletin no. 12: punching of structural concrete slabs. Lausanne: International Federation for Structural Concrete (fib); 2001.

[16] CEB-FIP. fib bulletin no. 45: practitioners' guide to finite element modelling of reinforced concrete structures. Lausanne: Switzerland: International Federation for Structural Concrete (fib); 2008.

[17] Hendriks MAN, den Uijl JA, de Boer A, Feenstr PH, Belletti B, Damoni C. Guidelines for nonlinear finite element analysis of concrete structures. Delft: Rijkswaterstaat Centre for Infrastructure; 2012.

[18] Guandalini S, Burdet OL, Muttoni A. Punching tests of slabs with low reinforcement ratios. ACI Struct J 2009:87-95.

[19] Guandalini S, Muttoni A. Symmetrical punching tests on slabs withou transverse reinforcement. Doctoral thesis. Lausanne, Switzerland; 2004

[20] EN 1992-1-1. Eurocode 2: Design of concrete structures - Part 1-1: General rules and rules for buildings. Brussels (Belgium): CEN European Committee for Standardization; 2004.

[21] TNO DIANA BV. Diana finite element analysis. TNO DIANA BV.; 2014.

[22] Shu J, Plos M, Zandi K, Johansson M. Development of modelling recommendations for assessment of RC bridge deck slabs using 3D 
continuum non-linear FE analysis. In: The 8th international conference on bridge maintenance, safety and management (IABMAS2016). p. 1-5.

[23] TNO. Diana finite element analysis. User's manual - release 9.6. Delft; 2015

[24] Cornelissen HAW, Hordijk Da, Reinhardt HW. Experimental determination of crack softening characteristics of normal weight and lightweight concrete. Heron. 1985;31(2):45-56.

[25] CEB-FIP. fib model code for concrete structures 1990. Lausanne: International Federation for Structural Concrete (fib); 1993.

[26] Thorenfeldt JJ, Tomaszewicz E, Jensen A. Mechanical properties of highstrength concrete and applications in design. In: Proc. symp. utilization of high-strength concrete.

[27] Mier J. Strain-softening of concreie under multiaxial loading conditions Doctoral thesis. Eindhoven: Eindhoven University of Technology; 1984.

[28] Zandi Hanjari K, Kettil P, Lundgren K. Modeling the structural behavior of frost-damaged reinforced concrete structures. Struct Infrastruct Eng 2013;9 (5):416-31.

[29] Selby RG, Vecchio FJ. A constitutive model for analysis of reinforced concrete solids. Can J Civ Eng 1997;24(3):460-70.

[30] CEB-FIP. fib model code for concrete structures 2010. Lausanne: International Federation for Structural Concrete (fib); 2013.
[31] Vecchio FJ, Collins MP. The modified compression field theory for reinforced concrete elements subjected to shear. ACI J 1986;83(22):219-31.

[32] Rots JG. Computational modeling of concrete fracture Doctoral thesis. Delft: Delft University of Technology; 1988.

[33] Shu J, Plos M, Zandi K, Lundgren K. A multi-level structural assessment proposal for reinforced concrete bridge deck slabs. Noric Concr Res 2015;2 (53):53-6.

[34] Muttoni A. Punching shear strength of reinforced concrete slabs by Aurelio Muttoni. ACI Struct J 2009;105:440-50.

[35] Menetrey P. Analytical computation of the punching strength of reinforced concrete. Struct J 1996;93(5):503-11.

[36] ACI Committee 318. Building code requirements for structural concrete and commentary. Farmington Hills (Mich): ACI American Concrete Institute; 2011.

[37] Bažant ZP, Cao Z. Size effect in punching shear failure of slabs. Struct J 1987;84 (1):44-53.

[38] Muttoni A, Ruiz MF. Shear strength of members without transverse reinforcement as function of critical shear crack width. ACI Struct J 2008;105(2):163-72. 